\title{
Orchidectomy versus oestrogen for prostatic cancer: cardiovascular effects
}

\author{
PETER HENRIKSSON, OLOF EDHAG
}

\begin{abstract}
One hundred consecutive patients aged up to 75 with newly diagnosed cancer of the prostate suitable for hormonal treatment were included in a controlled study of the cardiovascular effects of oestrogen versus orchidectomy. In all cases pre-existing cardiovascular morbidity was excluded.

Of the 100 patients, 91 were strictly randomised to receive either oestrogen $(n=47)$ or orchidectomy $(n=44)$ and $9(6$ given oestrogen, 3 orchidectomy) either chose their own treatment (five cases) or had it selected for them by the urologist (four). Oestrogen was given in the lowest recommended dosage in Sweden-namely, as $160 \mathrm{mg}$ polyestradiol phosphate intramuscularly every month for the first three months, then $80 \mathrm{mg}$ monthly, plus ethinyloestradiol $1 \mathrm{mg}$ by mouth daily for the first two weeks, then $150 \mu \mathrm{g}$ daily.

At entry to the study the two treatment groups showed no difference in demographic characteristics or conventional risk factors for cardiovascular disease. During the first year, however, $13(25 \%)$ of the patients given oestrogen suffered major cardiovascular events as compared with none of the patients after orchidectomy. Patients in the oestrogen treatment group who did not have minor signs of atherosclerosis at entry to the study suffered a similar incidence of cardiovascular complications to those who did have these signs at entry.

The substantially increased risk of cardiovascular complications in patients given oestrogen for prostatic cancer warrants careful consideration when choosing treatment for this disorder.
\end{abstract}

\section{Introduction \\ Oestrogen and orchidectomy were introduced as treatments for prostatic cancer by Huggins et al in 1941. ${ }^{1.3}$ The first report from the}

\footnotetext{
Cardiac Division, Department of Internal Medicine, Huddinge Hospital, Karolinska Institute, S-141 86 Huddinge, Sweden

PETER HENRIKSSON, MD, senior registrar

OLOF EDHAG, MD, PHD, associate professor

Correspondence and requests for reprints to: Dr Henriksson.
}

Veterans Administration Cooperative Urological Research Group appeared in 1967 and showed an increased cardiovascular mortality in diethylstilboestrol treated patients compared with non-oestrogen treatment. ${ }^{+}$A further study by the Veterans Administration showed that using a lower dose of oestrogen did not increase cardiovascular mortality. ${ }^{5}$ More recent evidence, however, suggests that even the lower dosages of oestrogen used today increase cardiovascular morbidity, ${ }^{6}$ but to our knowledge there has been no controlled study of oestrogen versus orchidectomy. In addition to reports on the adverse effects of oestrogen in patients with prostatic cancer, the Coronary Drug Project Research Group found increased cardiovascular and thromboembolic morbidity in men given oestrogen as secondary prophylaxis after myocardial infarction. ${ }^{7}$ In women oral contraceptives - certainly those with a high oestrogen contentalso increase cardiovascular morbidity. ${ }^{8}$

The aim of our study was to find out if there was a difference in cardiovascular morbidity in patients with prostatic cancer treated with today's dosages of oestrogen compared with orchidectomy.

\section{Patients and methods}

During November 1980 to July 1984, 122 consecutive patients aged up to 75 with newly diagnosed prostatic cancer suitable for hormonal treatment (as judged by a senior urologist) were considered for the study (see fig 1). Recruitment was in the department of urology at this hospital. Nineteen patients $(16 \%)$ were excluded owing to pre-existing cardiovascular morbidity-namely, myocardial infarction, cardiac decompensation, severe angina pectoris, severe intermittent claudication, cerebrovascular lesions, or thromboembolic episodes-and three further patients refused cardiovascular assessment. The remaining 100 patients were screened for a history of cardiovascular diseases or risk factors for such diseases and subjected to exercise stress tests, physiological evaluation of the peripheral circulation, and estimations of blood volume and lipoprotein and antithrombin III concentrations; they were also given a chest $x$ ray examination. Tumour states were $T_{1}$ ( 3 cases), $T_{2}(24), T_{3}(40)$, and $T_{4}(33)$.

Ninety one patients were strictly randomised to receive oestrogen treatment (47 patients) or orchidectomy (44), and the remaining nine either selected their own treatment (five patients) or received the treatment preferred by the urologist (four). Six of these nine received oestrogen and three were treated by orchidectomy (fig 1). The study was approved by the ethical committee of Huddinge University Hospital.

Minor signs of atherosclerosis-Patients were classified as having minor signs of atherosclerosis based on the results of a standardised bicycle exercise 
stress test and physiological evaluation of the peripheral circulation. The result of the exercise test was judged as pathological if there was a flat or down sloping ST segment depression from the baseline of at least $0.1 \mathrm{mV}$. Evaluation of the peripheral circulation consisted of digital pulse plethysmography and digital blood pressure measurement. Results were judged as pathological if there was an absence of dicrotism and a prolonged inclination time in the plethysmographic recording, or if there was difference of more than $30 \mathrm{~mm} \mathrm{Hg}$ between the brachial artery pressure and the blood pressure in the toe. Patients were classified as having minor signs of atherosclerosis if either the stress test or evaluation of the peripheral circulation yielded abnormal results.

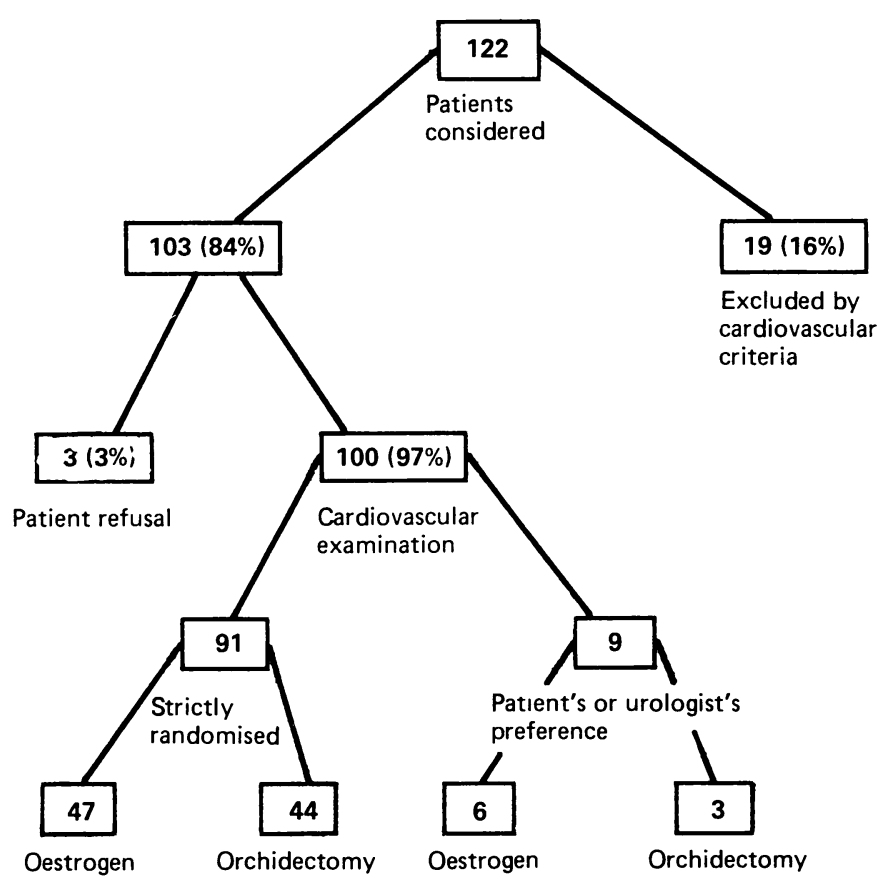

FIG 1-Exclusions and assignment to treatment of patients considered for study.

Treatment-Oestrogen was given as polyestradiol phosphate $160 \mathrm{mg}$ intramuscularly every month for three months, then $80 \mathrm{mg}$ intramuscularly per month. In addition, the patients received ethinyloestradiol $1 \mathrm{mg}$ by mouth daily for the first two weeks followed by $150 \mu \mathrm{g}$ daily. This dosage is the lowest recommended in Sweden for the treatment of prostatic cancer. Bilateral orchidectomy was performed under general anaesthesia.

Follow up and end points - All patients were followed up for at least one year, the last patient completing his year of follow up in August 1985. The end points of the study were identical with the exclusion criteria listed above-that is, major cardiovascular events comprising myocardial infarction, cardiac decompensation, severe angina pectoris (medically intractable), severe intermittent claudication (indication for reconstructive surgery), cerebrovascular thrombosis or emboli, and thromboembolic episodes. Patients who suffered a major cardiovascular event were withdrawn from oestrogen treatment and later subjected to orchidectomy.

Statistical analysis-Baseline characteristics of the orchidectomy and oestrogen treatment groups were compared by Student's $t$ test for unpaired samples. Major cardiovascular complications during the first year of treatment were compared using a life table technique.

\section{Results}

\section{BASELINE CHARACTERISTICS}

Demographic characteristics and conventional risk factors for cardiovascular disease-for example, age; weight; smoking habits; concentrations of cholesterol, high density lipoprotein cholesterol, triglycerides, and glucose; prevalence of diabetes; and systolic and diastolic blood pressuredid not differ between the two treatment groups (table I). There was also no difference in mean blood volume, antithrombin III activity, or creatinine concentration. Minor signs of atherosclerosis were present in $10(19 \%)$ of the patients in the oestrogen treatment group and $12(26 \%)$ of those in the orchidectomy group. This difference was not significant.
TABLE I-Baseline characteristics of oestrogen treatment and orchidectomy groups at entry to study. Except where stated otherwise values are means (SEM in parentheses)

\begin{tabular}{|c|c|c|}
\hline & $\begin{array}{l}\text { Oestrogen } \\
\text { group } \\
(\mathrm{n}=53)\end{array}$ & $\begin{array}{l}\text { Orchidectomy } \\
\text { group } \\
(n=47)\end{array}$ \\
\hline Age (years) & $67 \cdot 7(0 \cdot 8)$ & $68 \cdot 7(0 \cdot 8)$ \\
\hline Weight $(\mathrm{kg})$ & $74 \cdot 6(1 \cdot 6)$ & $74 \cdot 7(1 \cdot 7)$ \\
\hline Cholesterol (mmol l 1$)$ & $6 \cdot 0(0 \cdot 2)$ & $5 \cdot 9(0 \cdot 2)$ \\
\hline High density lipoprotein cholesterol $(\mathrm{mmol} / \mathrm{l})$ & $1 \cdot 24(0.05)$ & $1.26(0.05)$ \\
\hline Triglycerides $(\mathrm{mmol} 1)$ & $1.9(0.2)$ & $1.6(0.2)$ \\
\hline No $(\%)$ of smokers & $21 \quad(40)$ & $20 \quad(43)$ \\
\hline No $(\%)$ of previous smokers & $19 \quad(36)$ & (34) \\
\hline No $(\%)$ never smoked & $13 \quad(25)$ & $11 \quad(23)$ \\
\hline Years of smoking & $28 \cdot 0(2 \cdot 7)$ & $28 \cdot 5(2 \cdot 9)$ \\
\hline No $(\%)$ with diabetes & $2(4)$ & 2 (4) \\
\hline Fasting blood glucose $(\mathrm{mmol} / 1)$ & $5 \cdot 4(0 \cdot 2)$ & $5 \cdot 5(0 \cdot 2)$ \\
\hline No $(\%)$ with hypertension & $14 \quad(26)$ & $7 \quad(15)$ \\
\hline \multicolumn{3}{|l|}{ Blood pressure $(\mathrm{mm} \mathrm{Hg})$ : } \\
\hline Systolic & 152 & 151 \\
\hline Diastolic & $89 \quad(1)$ & $88 \quad(2)$ \\
\hline Blood volume (1) & $5 \cdot 4(0 \cdot 1)$ & $5 \cdot 3(0 \cdot 1)$ \\
\hline Serum antithrombin III (\%) & $81 \quad(2)$ & $77 \quad(2)$ \\
\hline Creatinine $(\mu \mathrm{mol} / 1)$ & 101 & 101 \\
\hline No $(\%)$ with minor signs of atherosclerosis & (19) & (26) \\
\hline
\end{tabular}

Conversion: SI to traditional units-Cholesterol and high density lipoprotein cholesterol: Com $103.6 \mathrm{mg} 100 \mathrm{ml}$ Triglycerides: $1 \mathrm{mmol} 1=88.5 \mathrm{mg} 100 \mathrm{ml}$. Glucose: $1 \mathrm{mmolh}$ $18.0 \mathrm{mg} 100 \mathrm{ml}$.

\section{MAJOR CARDIOVASCULAR EVENTS}

During the first year after initiation of hormonal treatment 13 patients suffered major cardiovascular events (table II). Three patients suffered myocardial infarctions (evidenced by conventional electrocardiographic and enzyme criteria); two developed intractable angina pectoris (confirmed by exercise stress tests and serial electrocardiograms with intermittent grossly abnormal ST-T changes); one had a cerebral infarction (computed tomography); one acquired severe intermittent claudication with definite changes in the estimated physiological variables of peripheral circulation and reduction in walking distance to less than $100 \mathrm{~m}$; four suffered deep vein thrombosis (confirmed by intravenous phlebography); and two developed congestive heart failure needing diuretics. No major cardiovascular events

TABLE II-Major cardiovascular events during one year follow up in the two treatment groups. Figures are numbers (percentage) of patients

\begin{tabular}{lcc}
\hline & $\begin{array}{c}\text { Oestrogen } \\
\text { group } \\
(\mathrm{n}=53)\end{array}$ & $\begin{array}{c}\text { Orchidectomy } \\
\text { group } \\
(\mathrm{n}=47)\end{array}$ \\
\hline Myocardial infarction & 3 & 0 \\
$\begin{array}{l}\text { Intractable angina pectoris } \\
\text { Cerebral infarction }\end{array}$ & 2 & 0 \\
$\begin{array}{l}\text { Severe intermittent claudication } \\
\text { Deep vein thrombosis } \\
\text { Cardiac failure }\end{array}$ & 1 & 0 \\
\hline Total & 4 & 0 \\
& 2 & 0 \\
\hline
\end{tabular}

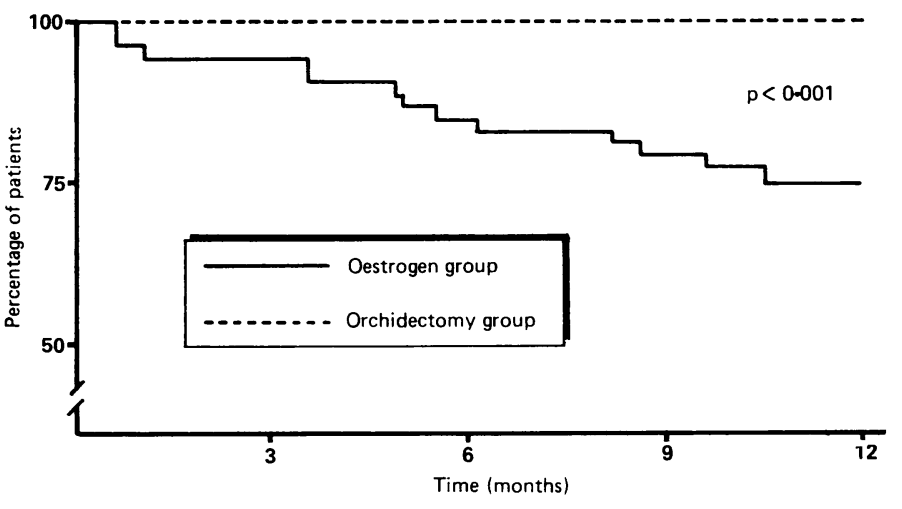

FIG 2-Proportions of patients in oestrogen treatment and orchidectomy groups not having major cardiovascular event during first year of treatment. 
occurred in the orchidectomy group. This difference between the two groups was significant at $\mathrm{p}<0.0008$.

The proportion of patients in the oestrogen treatment group who escaped a major cardiovascular event decreased gradually during the year (fig 2). At the end of the first year of treatment only $40(75 \%)$ of the patients had escaped having a major cardiovascular event as compared with all the patients in the orchidectomy group $(p<0.001)$.

The mean time from the onset of oestrogen treatment to a major cardiovascular event during the first year was $5 \cdot 1$ months (median 5.0). There was no significant difference in the incidence of major cardiovascular events between the patients in the oestrogen group recorded as having minor signs of atherosclerosis and those without signs of atherosclerosis (table III).

TABLE III-Incidence of major cardiovascular events in oestrogen treatment group in relation to prevalence of minor signs of atherosclerosis at entry to study

\begin{tabular}{lcc}
\hline & $\begin{array}{c}\text { Minor signs of } \\
\text { atherosclerosis } \\
(\mathrm{n}=10)\end{array}$ & $\begin{array}{c}\text { No sign of } \\
\text { atherosclerosis } \\
(\mathrm{n}=43)\end{array}$ \\
\hline $\begin{array}{l}\text { No }(\%) \text { having major cardiovascular event } \\
\text { No }(\%) \text { not having major cardiovascular event }\end{array}$ & $\begin{array}{l}3(30) \\
7(70)\end{array}$ & $\begin{array}{l}10(23) \\
33(77)\end{array}$ \\
\hline
\end{tabular}

In order to test the possibility of bias arising from nine patients not being strictly randomised to treatment we excluded these patients from the analysis. This resulted in a nearly identical proportion of patients as before escaping cardiovascular complications during the first year of oestrogen treatment $-76 \%$ compared with $100 \%$ without such complications in the orchidectomy group $(\mathrm{p}<0.0019)$.

\section{Discussion}

To our knowledge this is the first report on cardiovascular effects in a prospective controlled study of orchidectomy versus oestrogen given in the currently recommended dosage for the treatment of prostatic cancer. The study shows a highly significantly increased incidence of cardiovascular morbidity during the first year of oestrogen treatment compared with orchidectomy. This finding strongly favours the view that the cardiovascular morbidity during oestrogen treatment of prostatic cancer is due to the oestrogen alone and not to the elderly age group of men afflicted by this type of cancer. Most of the increased cardiovascular morbidity (54\%) consisted of arterial ischaemic disease-myocardial infarction, unstable angina pectoris, cerebral infarction, severe intermittent claudication. Deep vein thrombosis affected about a third of the victims. The median time from onset of oestrogen treatment to overt cardiovascular morbidity was five months. Our results accord with those of the Veterans Administration Cooperative Urological Research Group in patients receiving high dosage oestrogen treatment. ${ }^{4}$ The results are also in accordance with the cardiovascular morbidity in patients receiving oestrogen after myocardial infarction $^{7}$ and in women taking a contraceptive pill with high oestrogen content. ${ }^{8}$ In addition, a study comparing $3 \mathrm{mg}$ stilboestrol with the gonadotrophin releasing hormone analogue leuprolide showed a tendency towards an increased incidence of deep vein thrombosis and pulmonary embolism $(p=0.065)$ in the oestrogen treated group. ${ }^{9}$

It has been argued that patients with a history of cardiovascular disease have an increased incidence of cardiovascular complications during oestrogen treatment and we therefore excluded patients with pre-existing cardiovascular disease-namely, myocardial infarction, congestive heart failure, angina pectoris, intermittent claudication, cerebrovascular lesions, and thromboembolism. Furthermore, in the remaining patients we carried out exercise stress tests and physiological evaluation of the peripheral circulation, as might realistically be done in a clinical setting. Hence before randomisation patients were divided into one group showing no signs of atherosclerosis and a second group showing minor signs. There was no significant difference in the incidence of cardiovascular complications between these groups, though the proportion of patients with complications tended to be slightly higher in those with minor signs of atherosclerosis.

Ninety one of our patients were strictly randomised to treatment after cardiovascular assessment and nine were not, owing to a preference of these patients or the urologist for one or other treatment. In most of these cases oestrogen was preferred, probably for psychological reasons. It would not be realistic to expect to find a population of patients with prostatic cancer all willing to be randomised between oestrogen treatment or orchidectomy. Nevertheless, in our series there was no difference in the incidence of major cardiovascular events whether the analysis included all 100 patients or was confined to the group who were strictly randomised.

It is tempting to speculate on the pathogenesis of the cardiovascular complications during oestrogen treatment. An important factor may be blood coagulation, as the main inhibitor of blood coagulation, antithrombin III, is decreased during oestrogen treatment." Also the blood lipid composition changes during oestrogen treatment, with reduced low density lipoprotein cholesterol and increased high density lipoprotein cholesterol, ${ }^{11}$ though so far as we know this should not increase the risk of cardiovascular events. In addition, the serum triglyceride concentration increases, ${ }^{11}$ which may be unfavourable.

We conclude that the incidence of cardiovascular morbidity is increased during the first year of oestrogen treatment in patients with prostatic cancer, even when a low dosage regimen is used. This increased incidence affects patients either with or without clinically detectable atherosclerosis. It was too soon to comment on the clinical efficacy of the two treatments. Nevertheless, the high incidence of cardiovascular side effects in patients treated with oestrogen compared with orchidectomy should be considered in the choice of treatment for patients with prostatic cancer.

The study was supported by the Swedish National Association against Heart and Chest Diseases. We thank Kerstin Johansson for skilful preparation of the manuscript.

\section{References}

1 Huggins $C$, Hodges CV. Studies on prostatic cancer. I. The effects of castration, of estrogen and of androgen injection on serum phosphatases in metastatic carcinoma of the prostate. Cancer Res $1941 ; 1: 293-7$.

2 Huggins C, Stevens RE Jr, Hodges CV. Studies on prostatic cancer. II. The effects of castration in advanced carcinoma of the prostate gland. Arch Surg 1941;43:209-23.

3 Huggins $C$, Scott WW, Hodges CV. Studies on prostatic cancer. III. The effects of fever, of desoxycorticosterone and of estrogen on clinical patients with metastatic carcinoma of the prostate. F Urol 1941;46:997-1006.

4 Veterans Administration Cooperative Urological Research Group. Carcinoma of the prostate: treatment comparison. F Urol 1967;98:516-22.

5 Bailar JC III, Byar DP. Estrogen treatment for cancer of the prostate. Early results with 3 doses of diethylstilbestrol and placebo. Cancer 1970;26:257-61.

6 Hedlund PO, Gustafson H, Sjögren S. Cardiovascular complications to treatment of prostate cancer with estramustinephosphate or conventional estrogen. Scand $\mathcal{J}$ Urol Nephro $1980 ; 55$ (suppl):103-5.

7 Coronary Drug Project Research Group. The coronary drug project: initial findings leading to modifications of its research protocol. FAMA 1970;214:1303-13.

8 Stadel BV. Oral contraceptives and cardiovascular disease. N Engl f Med 1981;305:612-8, 672-7.

9 Leuprolide Study Group. Leuprolide versus diethylstilbestrol for metastatic prostate cancer. NEngl f Med 1984;311:1281-6.

10 Büller HR, Boon TA, Henny CP, Dabhoiwala NF, tenCate JW. Estrogen-induced deficiency and decrease in antithrombin III activity in patients with prostatic cancer. $\mathcal{F}$ Urol 1982;128:72-4.

11 Wallentin L, Varenhorst E. Plasma lipoproteins during anti-androgen treatment by oestrogens or orchidectomy in men with prostatic carcinoma. Horm Metab Res 1981;13:293-7.

(Accepted 23 fune 1986) 